\title{
ANALISA SISTEM PAKAR DIAGNOSA AWAL PENYAKIT AMEBIASIS DENGAN METODE CASE BASED REASONING
}

\author{
Dedi Rahman Habibie \\ Program Studi Sistem Informasi, STMIK GICI \\ email: dedi.habibi@gmail.com
}

\begin{abstract}
Abstrak
Amebiasis adalah penyakit infeksi usus besar yang disebabkan oleh parasit usus golongan protozoa yaitu spesies Entamoeba histolytica.t.[1]. Parasit ini dapat hidup di dalam atau permukaan kulit manusia yang merupakan gabungan dari beberapa parasit tunggal yang bertekstur seperti jeli. Banyak masyarakat yang tidak mengetahui informasi mengenai penyakit ini yang mengakibatkan penyakit semakit parah. Metode yang digunakan dalam sistem pakar ini adalah case based reasoning yang menggunakan kasus lama sebagai pembelajaran terhadap kasus baru dengan cara mencari nilai kemiripan dari kasus lama. Dengan adanya sistem pakar yang ini dapat menjadi alat untuk diagnosis awal terhadap penyakit Amebiasis sehingga masyarakat mengetahui langkah yang harus diambil jika terdiagnosis penyakit tersebut.
\end{abstract}

\section{Kata Kunci: Sistem Pakar, Case Based Reasoning, Amebiasis}

\section{PENDAHULUAN}

Pada masa saat sekarang ini masyarakat dihadapi akan kebutuhan dalam akan teknologi yang dapat dengan cepat dalam memberikan informasi yang akurat dan mudah didapatkan tanpa terhalang oleh ruang dan waktu. Kecerdasan buatan merupakan salah satu bentuk revolusi dalam bidang teknologi komputer.

Kecerdasan buatan atau sistem cerdas berasal dari kata Artificial Intelligence yang memiliki arti tiruan atau kecerdasan. Secara harfiah Artificial Intelligence merupakan kecerdasan buatan. Dengan kata lain Kecerdasan buatan adalah salah satu bidang dari ilmu komputer yang dapat membuat komputer supaya dapat bertindak dan sebaik seperti manusia (menirukan kerja otak manusia) [2]. Banyak penelitian mengenai kecerdasan buatan salah satunya yang diteliti oleh Yanuangga Gala Hartlambang, dkk (2015) yang menghasilkan peneltian berupa sistem kontrol kecapatan motor DC yang dianggap paling baik [3]. Dalam ilmu kecerdasan buatan terdapat salah satu cabang ilmu yaitu Sistem Pakar.

Sistem pakar merupakan salah satu bagian dari kecerdasan buatan yang mengandung pengetahuan dan pengalaman yang dimasukkan oleh satu atau banyak pakar ke dalam suatu area pengetahuan tertentu, sehingga setiap orang dapat menggunakannya untuk memecahkan berbagai masalah yang bersifat spesifik [4]. Banyak penelitian mengenai sistem pakar sudah banyak, diantaranya yaitu sistem pakar diagnosa penyakit limfoma yang diteliti oleh Dasril Aldo (2019) yang menghasilkan penelitian berupa sistem yang mampu mendiagnosa penyakit limfoma beserta pengobatannya. Dalam sistem pakar terdapat metode yang bisa digunakan diantaranya yaitu metode case based reasoning.

Metode Case Base Reasoning adalah suatu model penalaran yang 
menggabungkan pemecahan masalah, pemahaman dan pembelajaran serta memadukan ke seluruhannya dengan pemrosesan memori. Tugas tersebut dilakukan dengan memanfaatkan kasus yang pernah dialami oleh sistem, yang mana kasus merupakan pengetahuan dalam konteks tertentu yang mewakili suatu pengalaman yang menjadi dasar pembelajaran untuk mencapai tujuan sistem [5]. Penelitian lain mengenai metode Case Base Reasoning dilakukan oleh Minarni dan Indra Warman (2017) dengan judul "Sistem Pakar Identifikasi Penyakit Tanaman Padi Menggunakan Case-Based Reasoning" dengan hasil berupa sistem pakar yang dapat identifikasi penyakit tanaman padi dengan metode inferensi casebased reasoning dapat mengidentifikasi penyakit tanaman padi sesuai dengan kasus-kasus yang ada dalam basis kasus sebesar 100\% [6].

Amebiasis adalah penyakit infeksi usus besar yang disebabkan oleh parasit usus golongan protozoa yaitu spesies Entamoeba histolytica.t. Parasit ini sering ditemukan dalam usus besar manusia, primata tertentu dan beberapa hewan lain. Penyakit ini tersebar hampir di seluruh dunia terutama di negara sedang berkembang yang berada di daerah tropis. Hal ini disebabkan karena faktor kepadatan penduduk, individu, sanitasi lingkungan serta kondisi sosial ekonomi dan kultural yang menunjang. Di daerah dingin dengan keadaan sanitasi buruk, frekuensi penyakit ini setara di daerah tropis [1].

Alasan penulis melakukan penelitian ini adalah masih banyaknya masyarakat yang belum mengetahui informasi mengenai penyakit Amebiasis sehingga masayarakat mengabaikan gejala-gejala penyakit tersebut, jika dibiarkan begitu saja penyakit akan menjadi lebih parah bahkan dapat mengakibatkan timbulnya penyakit lainya.

Berdasarkan latar belakang permasalahan terebut maka peneliti tertarik untuk mengangkat judul penelitian sebagai berikut "Analisa Sistem Pakar Diagnosis Awal Penyakit Amebiasis Dengan Metode Case Based Reasoning".

\section{LANDASAN TEORI}

\section{Kecerdasan Buatan}

Kecerdasan buatan berasal dari kata Artificial Intelligence yang mengandung arti tiruan atau kecerdasan. Secara harfiah Artificial Intelligence adalah kecerdasan buatan. Kecerdasan buatan adalah salah satu bidang dalam ilmu komputer yang membuat komputer agar dapat bertindak dan sebaik seperti manusia (menirukan kerja otak manusia) [7].

\section{Metode CBR}

Case Based Reasoning (CBR) merupakan salah satu metode pemecahan masalah yang dalam mencari solusi dari suatu kasus yang baru, sistem akan melakukan pencarian terhadap solusi dari kasus lama yang memiliki permasalahan yang sama dan sudah pernah terjadi sebelumnya. Terdapat empat proses yang terjadi pada metode CBR dalam menyelesaikan masalah, yaitu [8]:

\section{a. Retrieve}

Mendapatkan/memperoleh kembali kasus yang paling menyerupai/ relevan (similar) dengan kasus yang baru. Tahap retrieval ini dimulai dengan menggambarkan/ menguraikan sebagian masalah, dan diakhiri jika ditemukannya kecocokan terhadap masalah sebelumnya yang tingkat kecocokannya paling tinggi. 
b. Reuse

Memodelkan/menggunakan

kembali pengetahuan dan informasi

kasus lama berdasarkan bobot kemiripan yang paling relevan ke dalam kasus yang baru, sehingga menghasilkan usulan solusi dimana mungkin diperlukan suatu adaptasi dengan masalah yang baru tersebut.

c. Revise

Meninjau kembali solusi yang diusulkan kemudian mengetesnya pada kasus nyata (simulasi) dan jika diperlukan memperbaiki solusi tersebut agar cocok dengan kasus yang baru.

d. Retain

Mengintegrasikan/ menyimpan kasus baru yang telah berhasil mendapatkan solusi agar dapat digunakan oleh kasus-kasus selanjutnya yang mirip dengan kasus tersebut.

\section{METODOLOGI PENELITIAN}

Kerangka penelitian adalah urutan yang akan dilakukan dalam suatu penelitian. Agar langkah-langkah yang diambil penulis dalam perancangan ini tidak melenceng dari pokok pembicaraan dan lebih mudah dipahami, maka urutan langkah-langkah penelitian akan dibuat secara sistematis sehingga dapat dijadikan pedoman yang jelas dan mudah untuk menyelesaikan permasalahan yang ada. Urutan langkah-langkah yang akan dibuat pada penelitian ini dapat dilihat pada gambar berikut ini :

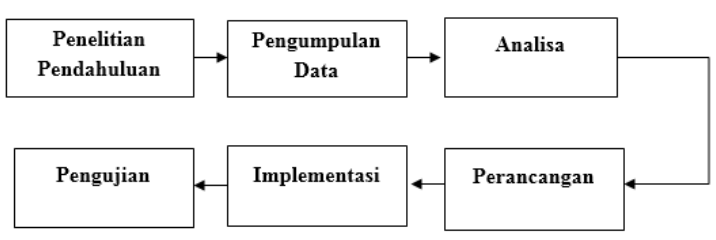

Gambar 1. Metodologi Penelitian

\section{HASIL DAN PEMBAHASAN}

\section{Analisa Data}

Proses analisa data yaitu merupakan salah satu tahapan yang penting dalam penelitian ini, karena pada tahap inilah nantinya dilakukan dentifikasi terhadap masalah yang ada dalam penelitian ini.

Analisa masalah dilakukan agar penemuan-penemuan masalah yang didapat dapat diketahui penyebabnya, sehingga dari analisa masalah tersebut didapatkan suatu bentuk pemecahan masalah.

Pemecahan masalah adalah suatu cara yang dapat menyelesaikan masalah yang telah dijelaskan pada analisa masalah di atas tersebut adalah dengan membangun sistem pakar ini.

\section{Analisa Proses Dengan Metode CBF}

Metode Case Base Reasoning adalah suatu model penalaran yang menggabungkan pemecahan masalah, pemahaman dan pembelajaran serta memadukan ke seluruhannya dengan pemrosesan memori.

Tabel 1. Kode Gejala

\begin{tabular}{|c|c|c|c|}
\hline NO & Kode & Gejala & Nilai \\
\hline 1 & G01 & $\begin{array}{c}\text { Diare (10 hingga } \\
12 \text { kali per hari) }\end{array}$ & 3 \\
\hline 2 & G02 & $\begin{array}{c}\text { Diare disertai } \\
\text { darah }\end{array}$ & 5 \\
\hline 3 & G03 & Kram pada perut & 1 \\
\hline 4 & G04 & $\begin{array}{c}\text { Buang air besar } \\
\text { yang kental }\end{array}$ & 3 \\
\hline 5 & G05 & Gas dalam perut & 1 \\
\hline 6 & G06 & Demam tinggi & 3 \\
\hline 7 & G07 & $\begin{array}{c}\text { Mudah Kelelahan } \\
\text { Sakit pada perut } \\
\text { bagian kanan }\end{array}$ & 5 \\
\hline 8 & G08 & $\begin{array}{c}\text { Tampak seperti } \\
\text { penyakit kuning }\end{array}$ & 3 \\
\hline 9 & G09 & & \\
\hline
\end{tabular}


Tabel 2. Persentase Diagnosis

\begin{tabular}{|c|c|c|}
\hline NO & Perentase & Keterangan \\
\hline 1 & 0.1 & $\begin{array}{c}\text { Definitely not (tidak } \\
\text { pasti) }\end{array}$ \\
\hline 2 & 0.2 & $\begin{array}{c}\text { Almost certainly not } \\
\text { (hampir tidak pasti) }\end{array}$ \\
\hline 3 & 0.3 & $\begin{array}{c}\text { Probably not } \\
\text { (kemungkinan besar } \\
\text { tidak) }\end{array}$ \\
\hline 4 & 0.4 & $\begin{array}{c}\text { Maybe not } \text { (mungkin } \\
\text { tidak) }\end{array}$ \\
\hline 5 & 0.5 & Kemungkinan kecil \\
\hline 6 & 0.6 & Maybe (mungkin) \\
\hline 7 & 0.7 & $\begin{array}{c}\text { Probably } \\
\text { (kemungkinan besar) }\end{array}$ \\
\hline 8 & 0.8 & $\begin{array}{c}\text { Almost certainty } \\
\text { (hampir pasti) }\end{array}$ \\
\hline 9 & 1 & Definitely (pasti) \\
\hline
\end{tabular}

Tabel 3. Konsultasi Pasien

\begin{tabular}{|c|c|c|c|}
\hline NO & Kode & Gejala & Jawaban \\
\hline 1 & G01 & $\begin{array}{c}\text { Diare (10 } \\
\text { hingga 12 kali } \\
\text { per hari) }\end{array}$ & YA \\
\hline 2 & G02 & $\begin{array}{c}\text { Diare disertai } \\
\text { darah }\end{array}$ & YA \\
\hline 3 & G03 & $\begin{array}{c}\text { Kram pada } \\
\text { perut }\end{array}$ & Tidak \\
\hline 4 & G04 & $\begin{array}{c}\text { Buang air } \\
\text { besar yang } \\
\text { kental }\end{array}$ & Tidak \\
\hline 5 & G05 & $\begin{array}{c}\text { Gas dalam } \\
\text { perut }\end{array}$ & YA \\
\hline 6 & G06 & Demam tinggi & YA \\
\hline 7 & G07 & $\begin{array}{c}\text { Mudah } \\
\text { Kelelahan }\end{array}$ & Ya \\
\hline 8 & G08 & $\begin{array}{c}\text { Sakit pada } \\
\text { perut bagian } \\
\text { kanan }\end{array}$ & Tidak \\
\hline 9 & G09 & $\begin{array}{c}\text { Tampak } \\
\text { seperti } \\
\text { penyakit } \\
\text { kuning }\end{array}$ & YA \\
\hline
\end{tabular}

Dari Tabel Tersebut akan

dilakukan proses CBR dengan Tahapan Sebagai berikut:

a. Retrieve

Proses ini yaitu dengan Mendapatkan/memperoleh kembali kasus yang paling menyerupai/ relevan (similar) dengan kasus yang baru dengan rumus seperti berikut:

Similiarity $($ problem, case $)=$

$$
\frac{s 1 * w 1+s 2 * w 2+. . s n * w n}{w 1+w 2+. . w n}
$$

Similiarity $($ problem, case $)=$ Keterangan :

$\mathrm{S}=$ Similiarity (nilai kemiripan), pada similiarity jika terdapat kemiripan kasus maka akan bernilai 1, sedangkan tidak mirip, maka bernilai 0

$\mathrm{W}=$ weight (bobot yang diberikan)

2. Reuse

Yaitu menggunakan kembali masalah atau kasus untuk mencoba memecahkan masalah atau kasus tersebut dan sistem akan melakukan penyesuaian terhadap kondisi kasus lama atau kasus pada tahap Retrive dengan kondisi saat ini.Sebagai contoh maka akan diambil pada kasus baru yang memiliki gejala sebagai berikut :

1. Diare (10 hingga 12 kali per hari), Bobot $=3$

2. Diare disertai darah, Bobot $=5$

3. Gas dalam perut, Bobot $=1$

4. Demam tinggi, Bobot $=3$

5. Mudah Kelelahan, Bobot $=1$

6. Tampak seperti penyakit kuning, Bobot $=3$

Dari kasus diaatas maka akan dilakukan perbandingan dengan 
seluruh kasus amebiasis yang lama, yaitu sebagai berikut :

1. Pencocokan Dengan Kasus amebiasis
a. Diare (10 hingga 12 kali per hari), Bobot $=3$
b. Diare disertai darah, Bobot $=5$
c. Gas dalam perut, Bobot $=1$
d. Demam tinggi, Bobot $=3$
e. Mudah Kelelaha, Bobot $=1$
f. Tampak seperti penyakit kuning, Bobot $=3$

Tabel 4. Tabel Pencocokan Kasus Lama Dengan Kasus Baru

\begin{tabular}{|cl|c|}
\hline Gejala Kasus Lama & $\begin{array}{c}\text { Bobot } \\
\text { Persamaan }\end{array}$ \\
\hline a. & $\begin{array}{l}\text { Diare (10 hingga } \\
\text { 12 kali per hari) }\end{array}$ & 1 \\
\hline b. & $\begin{array}{l}\text { Diare disertai } \\
\text { darah }\end{array}$ & 1 \\
\hline c. & Kram pada perut & 0 \\
\hline d. & $\begin{array}{l}\text { Buang air besar } \\
\text { yang kental }\end{array}$ & 0 \\
\hline e. & Gas dalam perut & 1 \\
\hline f. & Demam tinggi & 1 \\
\hline g. & Mudah Kelelahan & 1 \\
\hline h. & $\begin{array}{l}\text { Sakit pada perut } \\
\text { bagian kanan }\end{array}$ & 0 \\
\hline i. & $\begin{array}{l}\text { Tampak seperti } \\
\text { penyakit kuning }\end{array}$ & 1 \\
\hline
\end{tabular}

Ket : Jika Gejala Sama bernilai 1, jika berbeda maka 0

Dari persaman gejala tersebut maka akan dicari tingkat kemiripan nya, yaitu dengan rumus :

Similarity (problem, case)

$=\frac{(s 1 * w 1) \ldots \ldots \ldots \ldots \ldots+(s 9 * w 9)}{w 1+\cdots \ldots \ldots+w 9}$

dimana $\mathrm{s} 1$ = Bobot Kemiripan, w1 = bobot Gejala

$$
\begin{aligned}
& S \text { (problem, case) } \\
& (1 * 3)+(1 * 5)+(0 * 1)+(0 * 3)+(1 * 1) \\
& =\frac{+(1 * 3)+(1 * 1)+(0 * 5)+(1 * 3)}{3+5+1+3+1+3+1+5+3} \\
& S(\text { problem }, \text { case })=\frac{16}{25}=0,64
\end{aligned}
$$

Dari perhitungan kasus diatas, kasus yang memiliki bobot kemiripan 0.64 atau $64 \%$, berdasarkan tabel persentase maka pasien terdiagnosis penyakit amebiasis dengan predikat "Maybe (mungkin)".

\section{SIMPULAN}

Dari uraian masalah di atas, serta berdasarkan analisa dari bab-bab yang ada, maka dapat ditarik kesimpulan yaitu, sistem pakar dengan menggunakan metode CBR dapat mendiagnosis secara awal penyakit amebiasis, hal tersebut dibuktikan dari gejala yang dipilih pasien pada Tabel 3, pasien terdiagnosis penyakit amebiasis dengan nilai $64 \%$ yang merupakan hasil perhiungan dengan metode CBR.

\section{DAFTAR PUSTAKA}

Maryatun, M. (2008). Entamoeba histolytica: parasit penyebab amebiasis usus dan hepar. Jurnal Kedokteran Syiah Kuala, 8(1), 3946.

Octavina, Y., \& Fadlil, A. (2014). Sistem Pakar untuk Mendiagnosa Penyakit pada Saluran Pernafasan dan Paru menggunakan Metode Certainty Factor. Jurnal Sarjana Teknik Informatika, 2(2), 326335.

Hartlambang, Y. G., Ali, M., \& Raikhani, A. (2015). Unjuk Kerja Kecerdasan Buatan (Artificial Intelligence) Dalam Mengoptimalkan Kecepatan Motor Dc Dengan Menggunakan Metode Imperalistt Competitive 
Alghorithm (ICA). Jurnal Intake: Jurnal Penelitian Ilmu Teknik dan Terapan, 6(1), 51-67.

Aldo, D. (2019). Sistem Pakar Diagnosa

Penyakit Limfoma dengan Metode Certainty Factor. SATIN-Sains dan Teknologi Informasi, 5(1), 6069.

Shaid, M., Laksito, W., \& Utami, Y. R. W. (2015). Sistem Pakar Pertumbuhan Balita Berbasis Web dengan Metode Case Based Reasoning. Jurnal Teknologi Informasi dan Komunikasi (TIKomSiN), 3(1).

Minarni, M., \& Warman, I. (2017). Sistem Pakar Identifikasi Penyakit Tanaman Padi Menggunakan Case-Based Reasoning. In Seminar Nasional Aplikasi Teknologi Informasi 2017. Islamic University of Indonesia. 7(2), 8792.

Octavina, Y., \& Fadlil, A. (2014). Sistem Pakar untuk Mendiagnosa Penyakit pada Saluran Pernafasan dan Paru menggunakan Metode Certainty Factor. Jurnal Sarjana Teknik Informatika, 2(2), 326-335.

Putri, T. E., Andreswari, D., \& Efendi, R. (2016). Implementasi Metode CBR (Case Based Reasoning) Dalam Pemilihan Pestisida Terhadap Hama Padi Sawah Menggunakan Algoritma KNearest Neighbor (KNN) (Studi Kasus Kabupaten Seluma). Rekursif: Jurnal Informatika, 4(1). 